\title{
Background pathology of the ovary in a laboratory population of zebrafish Danio rerio
}

\author{
Stefanie Rossteuscher ${ }^{1}$, Heike Schmidt-Posthaus ${ }^{1}$, Christoph Schäfers ${ }^{2}$, \\ Matthias Teigeler ${ }^{2}$, Helmut Segner ${ }^{1, *}$ \\ ${ }^{1}$ Centre for Fish and Wildlife Health, University of Bern, PO Box 8466, 3001 Bern, Switzerland \\ ${ }^{2}$ Fraunhofer Institute for Molecular Biology and Applied Ecology IME, 57392 Schmallenberg, Germany
}

\begin{abstract}
Adult zebrafish Danio rerio originating from one stock used as control animals in a toxicological study were examined histopathologically for the occurrence of spontaneous lesions in the gonads. While no histopathological changes were seen in the testes, the ovaries showed lesions consisting mainly of acute granulomatous inflammation with increased atresia and the presence of egg debris in the ovarian parenchyma and in the oviduct. Since infectious agents could not be detected and the fish were not exposed to toxicants, we consider these lesions as spontaneous alterations of the ovaries.
\end{abstract}

KEY WORDS: Zebrafish · Gonad · Histopathology

Resale or republication not permitted without written consent of the publisher

\section{INTRODUCTION}

The zebrafish Danio rerio is used as a test species, amongst others, for assessing endocrine-disrupting activities of chemical substances. One potential endpoint for detecting hormonal activities of test compounds is gonad histopathology (van der Ven et al. 2003). However, information on the background pathology of zebrafish gonads is scanty (Spitsbergen \& Kent 2003) and restricted to responses to infections by Mycobacteria spp. and Microsporidia sp. (Talaat et al. 1999, Astrofsky et al. 2000, Kent et al. 2004). In this note, we report on the occurrence of background pathologies in the gonads of 97 adult zebrafish kept as control animals of a toxicity study.

\section{MATERIALS AND METHODS}

Sexually mature zebrafish at an age of 3 mo (59 females, 38 males) originating from one breeding group from the laboratories of Fraunhofer IME,
Schmallenberg, Germany, were used as control fish in a $21 \mathrm{~d}$ screening test with endocrine disrupting substances. Mortality during the experimental period was below $5 \%$. Mean egg production female ${ }^{-1} \mathrm{~d}^{-1}$ was $54.13 \pm 26.58$. At the end of the experiment fish were euthanized by an overdose of chloro-butanol (20 $\left.\mathrm{g} \mathrm{l}^{-1}\right)$. The middle part of the body containing the gonads was fixed in $10 \%$ buffered formalin, embedded in paraffin, and sectioned at 3 to $5 \mu \mathrm{m}$. Sections were routinely stained with haematoxylin and eosin (H\&E), while additional sections were stained with periodic acidSchiff's reagent (PAS), Ziehl Neelson, Fite-Faraco or Grocott's Methenamine Silver.

\section{RESULTS AND DISCUSSION}

The histological evaluation of the gonads revealed normal morphological features in the testes. In females, however, only $22 \%$ fish showed the typical ovarian morphology (Fig. 1) as described for zebrafish reared under control conditions (e.g. van der Ven et al. 


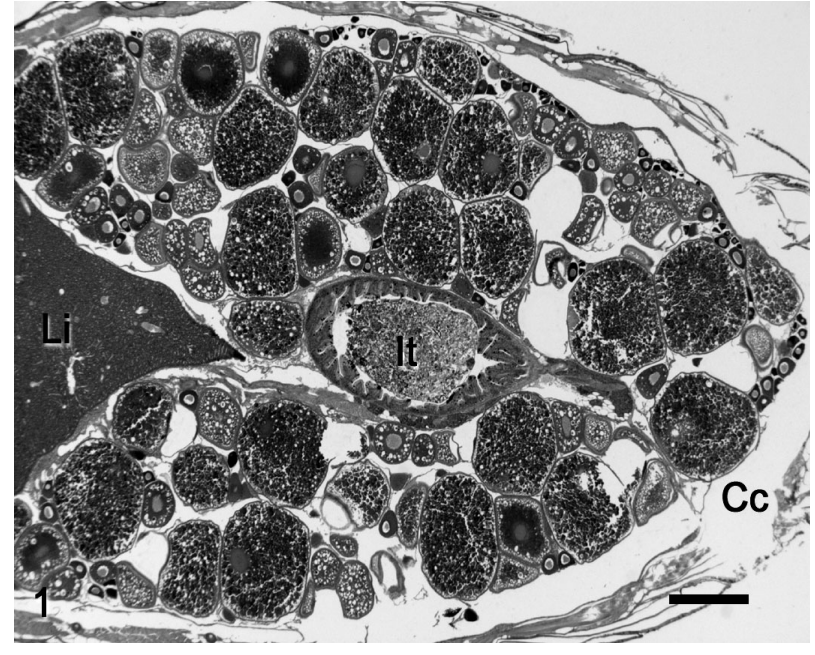

Fig. 1. Danio rerio. Normal ovary of mature zebrafish showing oocytes of different maturation stages. Li: liver; It: intestine;

Cc: coelomic cavity. Scale bar $=500 \mu \mathrm{m}$
2003), while the ovaries of the remaining $78 \%$ females ( $\mathrm{n}=46$ ) displayed pathological alterations. The most noticeable changes were an increased frequency of atresia of mature oocytes (observed in $58 \%$ of the females), and the presence of 'egg debris' (observed in $53 \%$ of the females). In $42 \%$ of the 59 control females examined, both alterations - increased frequency of atresia of mature oocytes and egg debris - were present. This association was significant $(\mathrm{p}<0.05$, chisquare test).

Increased atresia of mature oocytes was characterized by loss of oocyte shape, together with a collapse of the chorion (Figs. $2 \& 3$ ). The yolk stained more basophilic and displayed irregular fragmentation. Phagocytosis of yolk by follicular (presumably granulosa) cells was frequently observed (Fig. 3). Egg debris could be found both in the ovarian parenchyma and in the oviduct (Fig. 4). It was composed of follicle remnants (chorion fragments, degenerated follicular cells and
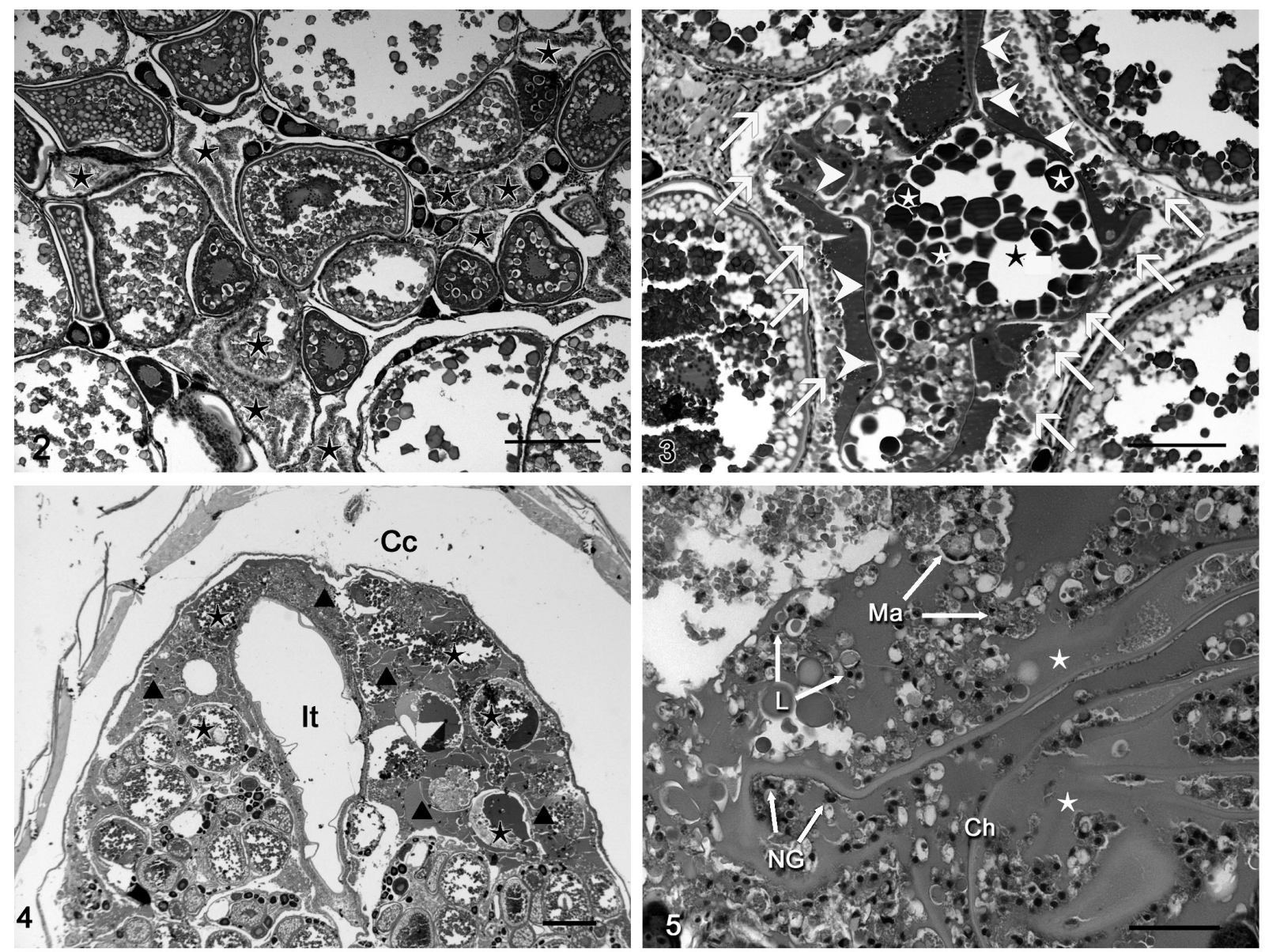

Figs. 2 to 5. Danio rerio. Pathological changes of ovaries of adult zebrafish. Fig. 2. Microscopic lesion of ovary. Increased numbers of atretic mature oocytes $(\star)$. Scale bar $=200 \mu \mathrm{m}$. Fig. 3. Atresia of mature oocyte: collapse of the chorion (arrowheads), irregular fragmentation of yolk $(\star)$; phagocytosis of yolk by follicular cells (arrows). Scale bar $=100 \mu \mathrm{m}$. Fig. 4. Overview of an ovary, with large areas occupied by egg debris. $\star$ : remnants of mature oocytes; $\mathbf{\Delta}$ : leaked yolk; It: intestine; Cc: coelomic cavity. Scale bar $=$ $500 \mu \mathrm{m}$. Fig. 5. Infiltration of the ovary with inflammatory cells (Ma: macrophages; L: lymphocytes; NG: neutrophilic granulocytes) intermingled with egg debris (Ch: remnants of chorion; $\star$ : leaked yolk). Scale bar $=100 \mu \mathrm{m}$ 
degenerated yolk) admixed with homogenously eosinophilic, translucent material, which presumably represents leaked yolk. Areas with egg debris were infiltrated with numerous foamy macrophages, a few lymphocytes and epitheloid macrophages and scattered neutrophilic granulocytes (Fig. 5). Multinucleated giant cells were also observed but at low frequency. These inflammatory features correspond to a granulomatous inflammation. No evidence for the presence of bacteria including acid fast bacilli or fungal hyphae as possible causes of the inflammatory response could be obtained in H\&E or in the special stainings.

Pathogenetic processes that could lead to the observed lesions are either a primary inflammatory process followed by increased atresia of mature oocytes and egg debris, or a primary degenerative process with a secondary granulomatous reaction. Although the inability to detect parasites, fungi or acid-fast bacteria argues against a primary inflammatory process as the cause of the observed lesions, we cannot fully exclude the possibility that infectious agents are involved. For instance, Watral \& Kent (2007) pointed out that staining of acid-fast bacteria may remain negative even when molecular methods or bacterial cultures succeed in demonstrating the presence of mycobacteria. However, if infectious agents were responsible for the observed lesions, then both males and females would be affected, but in our study pathological alterations occurred only in females. Further, it has been reported that granulomatous and inflammatory changes in mycobacterial-infected zebrafish occur mainly in organs other than the ovaries (Watral \& Kent 2007), which is in contrast to our fishes, where lesions occurred in the ovaries. All things considered, it is not likely that infectious agents were the cause of the ovarian changes in the control zebrafish; rather, we consider non-infective factors to be responsible.

A non-infective factor which might cause ovarian pathologies is damage to the eggs during ovulation or failure of ovulation. This condition can lead to atresia and resorption of oocytes, accompanied by infiltration of ovarian parenchyma and the oviduct by macrophages and melano-macrophages as well as proliferation of fibrous tissue in the stroma of the ovary, but with the occurrence of egg debris (Roberts 2001, Ferguson et al. 2006). In the females in our study, egg retention is unlikely to be the cause of the ovarian pathologies, since the females showed an egg production comparable to egg production of breeding groups from earlier studies in which females showed normal ovarian morphology (C. Schäfers unpubl. data).

For zebrafish, a lesion described to be specific to the ovary is the so-called 'egg-associated inflammation' (EAI) syndrome (Kent et al. 2002, Matthews 2004; http://zebrafish.org/zirc/health/diseaseManual.php).
The EAI syndrome is characterized by degenerating follicles in association with chronic inflammatory changes. In severe cases, fibroplasias and fibrosarcomas may develop. In accordance with our findings, an association of the EAI disease with infectious agents has not been shown to date (Kent et al. 2004). From these observations, it appears that zebrafish females can develop non-infectious, spontaneous pathological alterations in the ovarian morphology. The manifestation of these spontaneous lesions might be stock- or strain-specific. We examined histologically the ovaries of control zebrafish from several other stocks and found no or little inflammatory and/or degenerative changes. In addition, the ovarian pathologies were not present in earlier studies even within the stock used for the present study. Thus, these lesions do not appear to be a permanent feature but can appear and disappear, with the factors favoring their manifestation remaining enigmatic.

The occurrence of apparently spontaneous ovarian lesions in zebrafish has been mentioned by other authors as well (Kent et al. 2002, Matthews 2004; http://zebrafish.org/zirc/health/diseaseManual.php). Importantly, similar changes to those described here for control fish have been reported to result from exposure to endocrine-disrupting compounds (van der Ven et al. 2003, 2007, Wester et al. 2003). This may lead to problems when using gonad histopathology as an endpoint in fish toxicity tests. If only a low number of samples are analysed per treatment, random variation in lesion frequency between controls and treatments may lead to misinterpretation of results. Even when larger numbers of fish are examined, the spontaneous lesions could confound the assessment of treatment-induced lesions and might render the experiment invalid.

In conclusion, this study indicates that degenerative and inflammatory alterations can occur apparently spontaneously in ovaries of zebrafish. This observation emphasises the importance of knowing baseline variations in target organ morphology to be able to evaluate chemically induced pathologies.

\section{LITERATURE CITED}

Astrofsky KM, Schrenzel MD, Bullis RA, Smolowitz RM, Fox JG (2000) Diagnosis and management of atypical Mycobacterium spp. infections in established laboratory zebrafish (Brachydanio rerio) facilities. Comp Med 50: 666-672

Ferguson H, Bjerkas E, Evensen O (2006) Systemic pathology of fish: a text book and atlas of normal tissues in teleost and their responses in disease. Scotian Press, Edinburgh

Kent ML, Spitsbergen JM, Matthews JM, Fournie JW, Westerfield M (2002) Diseases of zebrafish in research facilities. Zebrafish International Resource Center, Eugene, OR. Available at: http://zebrafish.org/zirc/health/diseasemanual.php (accessed 20 June 2007) 
Kent ML, Whipps CM, Matthews JL, Florio D and others (2004) Mycobacteriosis in zebrafish (Danio rerio) research facilities. Comp Biochem Physiol Part C: Toxicol Pharmacol 138:383-390

Matthews JL (2004) Common diseases of laboratory zebrafish. Methods Cell Biol 77:617-643

Roberts R (2001) Fish pathology. WB Saunders, London

Spitsbergen JM, Kent ML (2003) The state of the art of the zebrafish model for toxicology and toxicologic pathology research-advantages and current limitations. Toxicol Pathol 31:62-87

Talaat AM, Trucksis M, Kane AS, Reimschuessel R (1999) Pathogenicity of Mycobacterium fortuitum and Mycobacterium smegmatis to goldfish, Carassius auratus. Vet Microbiol 66:151-164

Editorial responsibility: Thomas Braunbeck, Heidelberg, Germany van der Ven LT, Wester PW, Vos JG (2003) Histopathology as a tool for the evaluation of endocrine disruption in zebrafish (Danio rerio). Environ Toxicol Chem 22:908-913

van der Ven LT, van den Brandhof EJ, Vos JH, Wester PW (2007) Effects of the estrogen agonist $17 \beta$-estradiol and antagonist tamoxifen in a partial life-cycle assay with zebrafish (Danio rerio). Environ Toxicol Chem 26:92-99

Watral V, Kent ML (2007) Pathogenesis of Mycobacterium spp. in zebrafish (Danio rerio) from research facilities. Comp Biochem Physiol Part C Toxicol Pharmacol 145: $55-60$

Wester PW, van den Brandhof EJ, Vos JH, van der Ven LT (2003) Identification of endocrine disruptive effects in the aquatic environmental partial life cycle assay in zebrafish. RIVM report 640920001/2003, RIVM, Bilthoven

Submitted: August 31, 2007; Accepted: January 8, 2008

Proofs received from author(s): March 14, 2008 